\title{
LONG-TERM RESULTS OF PROXIMAL FEMORAL REPLACEMENT FOR NON-NEOPLASTIC DISORDERS
}

ARTHUR L. MALKANI, JEFFREY J. SETTECERRI, FRANKLIN H. SIM,
EDMUND Y. S. CHAO, STEVEN L. WALLRICHS

From the Mayo Clinic and Mayo Foundation, Rochester, USA

We reviewed retrospectively 50 consecutive total hip arthroplasties with proximal femoral replacement prostheses in 49 patients. All the patients had massive bone loss. There were 31 women and 18 men who had undergone a mean of 3.1 hip operations. At the last review, 15 patients had died and two had been lost to follow-up, so that 32 patients ( 33 hips) were available for assessment. The mean age of the patients at the time of the operation was 60.6 years. The mean length of clinical follow-up was $11.1 \pm 4$ years, and mean radiographic follow-up was $7.6 \pm \mathbf{3 . 2}$ years.

The average preoperative Harris hip score was $46 \pm$ 13 points, which improved to $80 \pm 10$ points after one year and to $76 \pm 16$ points at the latest follow-up. The most frequent complication was dislocation, which occurred in 11 hips. Four femoral components and seven acetabular prostheses were revised because of aseptic loosening. With revision as the end point, survivorship after total hip arthroplasty with a proximal femoral replacement prosthesis was predicted to be $64 \%$ at 12 years.

Although our preliminary results of hip salvage with a proximal femoral replacement prosthesis were encouraging, a longer follow-up has shown a higher rate of failure.

$J$ Bone Joint Surg [Br] 1995;77-B:351-6.

Received 27 June 1994; Accepted 25 August 1994

A. L. Malkani, MD, Senior Resident

J. J. Settecerri, MD, Senior Resident

Mayo Graduate School of Medicine, Rochester, Minnesota, USA.

F. H. Sim, MD, Consultant, Department of Orthopaedics, Mayo Clinic and Mayo Foundation, and Professor of Orthopaedics, Mayo Medical School, Rochester, Minnesota, USA.

E. Y. S. Chao, PhD, Consultant, Division of Orthopaedic Research, Mayo Clinic and Mayo Foundation, and Professor of Orthopaedics, Mayo Medical School, Rochester, Minnesota, USA.

S. L. Wallrichs, BS, Statistician, Section of Biostatistics

Mayo Clinic and Mayo Foundation, 200 First Street SW. Rochester, Minnesota 55905, USA.

Correspondence should be sent to Dr F. H. Sim.

(1)1995 British Editorial Society of Bone and Joint Surgery 0301-620X/95/3965\$2.00
Salvage of the hip in patients with massive loss of proximal femoral bone can be very difficult. The aim is to relieve pain and to restore function, but the options for treatment are limited because of the loss of integrity of the proximal femur (Allan et al 1991). Resection arthroplasty is not satisfactory since it can leave a markedly shortened limb, with very reduced walking ability (Kantor et al 1986). The use of conventional long-stem femoral components is precluded because of the extent of the proximal femoral bone loss. We decided to use total hip arthroplasty with a femoral prosthesis which would replace the bone lost from the proximal femur and would articulate with the acetabulum.

Our initial results were encouraging ( $\mathrm{Sim}$ and Chao 1981), with two failures in the first 21 patients. We cautioned that the results were preliminary and that a longer period of follow-up would be required to test the efficacy of this type of reconstruction.

We now report the long-term results in patients who underwent hip salvage by prosthetic replacement of the proximal femur and define the role of this type of reconstruction compared with others which have become available (Gross et al 1985; Head, Malinin and Berklacich 1987; Emerson et al 1990; Allan et al 1991).

\section{PATIENTS AND METHODS}

Between September 1972 and January 1986, we performed 50 total hip arthroplasties using a proximal femoral replacement prosthesis in 49 patients with non-neoplastic conditions. All had significant loss of bone in the proximal femur which was replaced by the prosthesis (Fig. 1). All the femoral components had the same design but varied in length, with a nearly anatomical neck length and neck-shaft angle. The proximal segment of the component was designed to replace the bone loss and varied from 60 to $200 \mathrm{~mm}$ in length. The distal stem was $16 \mathrm{~cm}$ in length and had a cross-sectional shape resembling an I-beam. It was fixed in the intramedullary part of the residual host bone with polymethylmethacrylate cement.

At the time of review, 15 patients had died and two had been lost to follow-up. Three patients were excluded from analysis because of inadequate radiographs, leaving 30 hips in 29 patients for final review. One patient had both hips affected. The mean age at review was $60.6 \pm 14.3$ years ( 27 to 82 ), and the mean weight was $69.3 \mathrm{~kg}$ ( 44.6 to 94.5 ). The mean length of clinical follow-up was $11.1 \pm 4$ years (5.1 to 


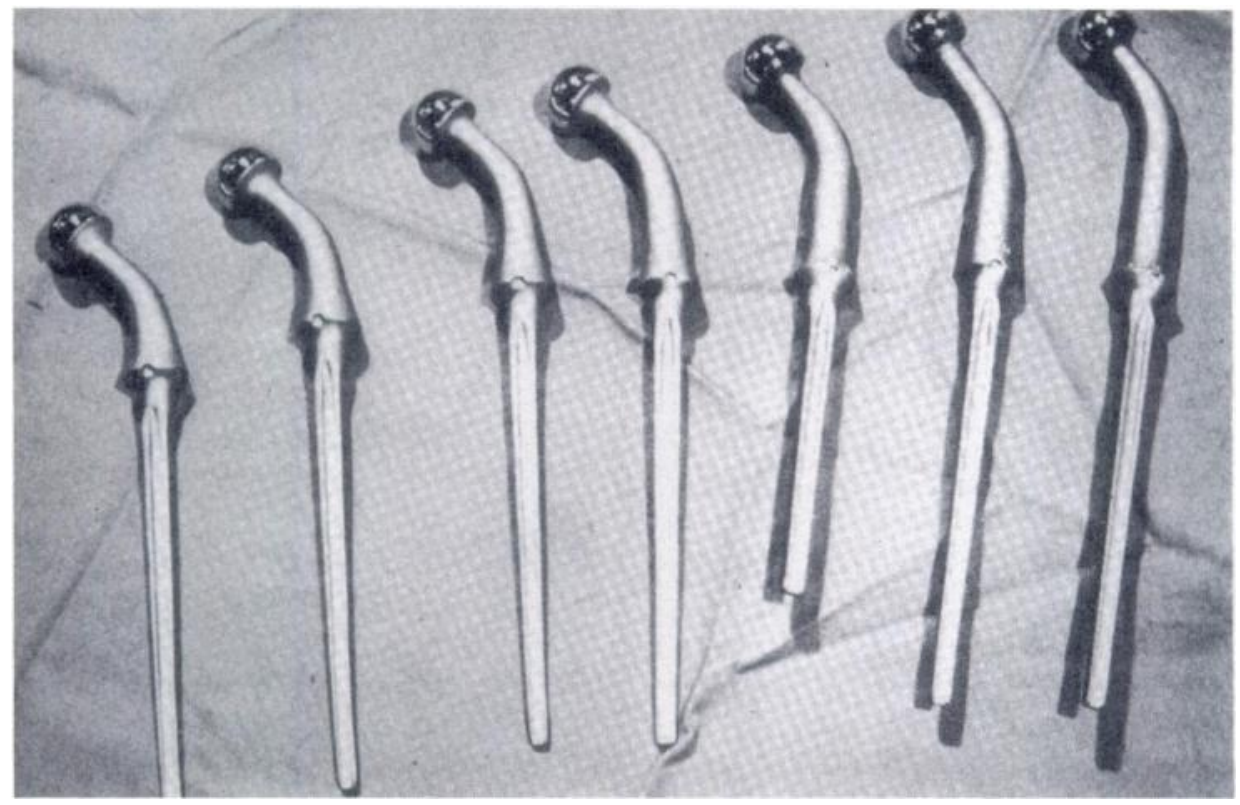

Fig. 1

First-generation proximal femoral replacement prostheses (from Sim and Chao (1981), by permission of the $J$ Bone Joint Surg $[A m])$.

18.8), and the mean radiographic follow-up was $7.6 \pm 3.2$ years ( 3.2 to 15.1$)$.

The underlying reason for the salvage operation was a failed total hip arthroplasty in 34 hips (aseptic femoral component loosening in 26, periprosthetic hip fracture in 3 , salvage of a Girdlestone procedure in 5), osteoarthritis of the hip with severe proximal femoral fracture in 15, and conversion of an arthrodesis in one. In all patients proximal bone loss precluded the use of a standard femoral component. Femoral deficiency was classified according to the criteria of the AAOS Committee on the Hip (1990); $50 \%$ of our patients had combined cortical and cancellous bone loss extending well beyond the level of the lesser trochanter (type III, level III). There was femoral discontinuity in $41 \%$.

The surgical technique of total hip arthroplasty using a proximal femoral replacement prosthesis is demanding and has been described previously (Sim and Chao 1981). The length of the prosthesis is determined before operation by the extent of the femoral bone loss. The proximal femur is sectioned at a level that can support the prosthesis, and the canal is prepared for intramedullary stem fixation. A trial reduction assesses stability and soft-tissue tension, which must be sufficient to provide joint stability and avoid dislocation. The greater trochanter is usually deficient or absent.

The acetabular and femoral components are secured in place with bone cement after a satisfactory trial reduction. At closure, the abductor mechanism is attached to the vastus lateralis if there is adequate length or else sutured to the undersurface of the tensor fasciae latae. In most cases the operation was performed before the introduction of modern cementing techniques.
Hip scores were calculated using both the Harris and the Mayo Clinic systems (Kavanagh and Fitzgerald 1985). Radiographic data were obtained from anteroposterior and lateral views of the hip and femur. Radiographs were evaluated preoperatively, at one year postoperatively, and at the latest follow-up. Zones 1 to 10 were assigned to the femoral stem for radiographic analysis (Fig. 2). Acetabular radiolucent lines were measured by the technique described by DeLee and Charnley (1976).

Statistical analysis was performed with paired $t$-tests and the signed-rank test to compare preoperative and postoperative hip scores and the incidence of postoperative radiolucent lines. Wilcoxon rank-sum tests and analysis variants were used to determine the relationship between component alignment, length and clinical hip scores and radiolucent lines. With revision as an end point, a survivorship curve was generated using the Kaplan and Meier (1958) method.

\section{RESULTS}

The mean preoperative Harris hip score for the study group was $46 \pm 13$ points ( 31 to 83 ). This had improved to $80 \pm$ 10 points ( 50 to 91 ) by one year after operation and to 76 \pm 16 points $(41$ to 94$)$ at the latest follow-up $(\mathrm{p}<0.01)$. The mean preoperative Mayo Clinic hip score was $30 \pm 17$ points (range 11 to 60; maximum obtainable, 80 points; Kantor et al 1986). One year after operation and at the latest follow-up the scores were $63 \pm 9$ points (35 to 75) and $57 \pm 18$ points $(18$ to 75$)$, respectively $(\mathrm{p}<0.01)$. Before operation $86 \%$ of the patients had moderate to severe pain (Table I). By one year after operation only $12 \%$ of the patients had moderate to severe pain but this had 
Table I. Evaluation of hip function after proximal femoral replacement in 29 patients ( 30 hips) by percentage*

\begin{tabular}{lllll}
\hline & Patients & & & \\
\cline { 2 - 5 } & Preoperatively & $\begin{array}{l}\text { One year } \\
\text { postoperatively }\end{array}$ & $\begin{array}{l}\text { At latest } \\
\text { follow-up }\end{array}$ & p value \\
\hline Moderate to severe pain & 86 & 12 & 27 & $<0.0001$ \\
Severe limp or unable to walk & 92 & 26 & 48 & $<0.01$ \\
Need a walking aid & 83 & 69 & 65 & $<0.01$ \\
Walking outdoors & 60 & 86 & 72 & NS \\
\hline
\end{tabular}

* data from Malkani, Sim and Chao (1993)

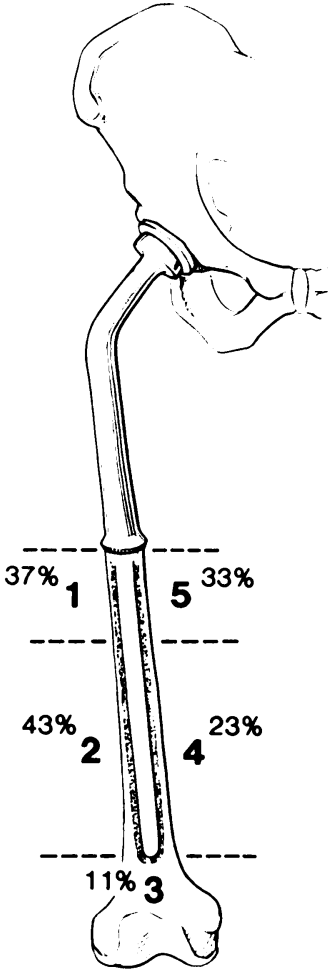

Fig. 2a

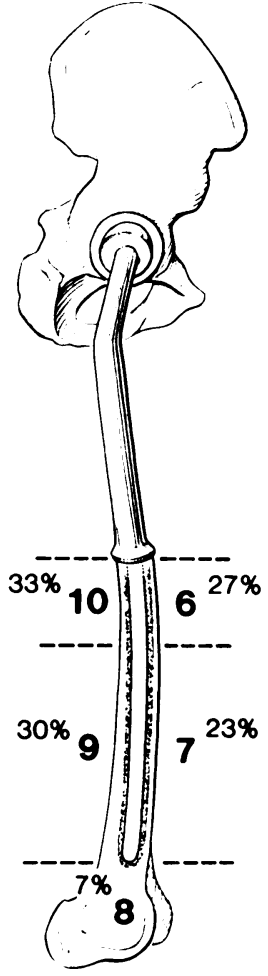

Fig. $2 b$
Assignment of zones 1 to 10 for radiographic analysis of loosening at the cement-bone interface of the femoral component. Percentages refer to radiolucent lines. Figure $2 \mathrm{a}$ - Anteroposterior projection, zones 1 to 5 . Figure $2 \mathrm{~b}-$ Lateral projection, zones 6 to 10 .

increased to $27 \%$ at latest follow-up. Before operation $92 \%$ of the patients had a severe limp or were unable to walk. One year later, however, only $26 \%$ of the patients had a severe limp or were unable to walk, but this had increased to $48 \%$ at the latest follow-up.

Before operation $40 \%$ of the patients could either walk only indoors or were wheelchair-bound. By one year and at the latest follow-up this had decreased to $14 \%$ and $28 \%$, respectively, but the difference was not significant. Fulltime use of a cane or crutches was needed for walking by $83 \%$ of the patients preoperatively, by $69 \%$ one year after operation and by $65 \%$ at the latest follow-up $(\mathrm{p}<0.01)$. The range of hip motion at the latest follow-up showed an average flexion of $90^{\circ} \pm 17^{\circ}$, abduction of $35^{\circ} \pm 12^{\circ}$, adduction of $24^{\circ} \pm 11^{\circ}$, external rotation of $43^{\circ} \pm 19^{\circ}$ and internal rotation of $20^{\circ} \pm 9^{\circ}$; these values were similar to those seen at one year postoperatively.

Progressive radiolucent lines at the cement-bone interface of the femoral component were predominantly located in zones 1, 2, 4, 6 and 9 (Fig. 2). Zone 1, the proximal lateral aspect of the stem located at mid-femur, had a $37 \%$ incidence of radiolucent lines measuring $2 \mathrm{~mm}$ or more ( $p<0.01$ ), and zone 2, the distal lateral aspect of the stem, had a $43 \%$ incidence of such lines $(p<0.05)$ at the last follow-up. On the acetabular side, the incidence of progressive radiolucent lines at the cement-bone interface in zone 1 increased from $4 \%$ at one year after operation to $20 \%$ at the latest follow-up $(p<0.01)$ in the patients who did not have revision (Fig. 3). In zone 2, the incidence of progressive radiolucent lines increased from $4 \%$ at one year to $30 \%$ at the latest follow-up ( $<<0.01$ ), and in zone 3 , this incidence had increased from $15 \%$ at one year to $37 \%$ at the latest follow-up ( $p<0.05)$.

By the last review 16 components in 12 patients (Table II) had required further revision. Four were performed

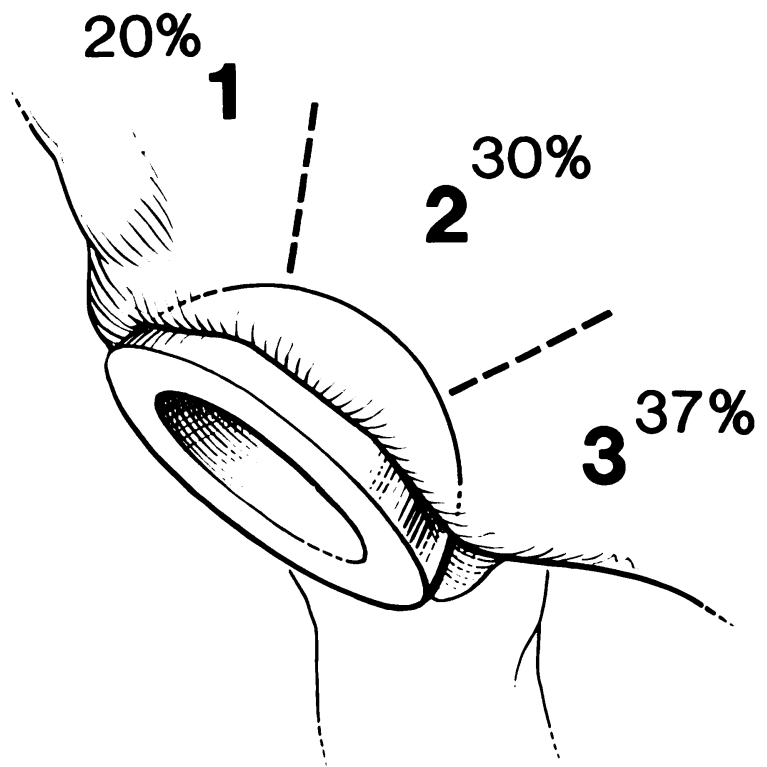

Fig. 3

Radiolucent lines $\mathbf{2} \mathrm{mm}$ or greater at the acetabular cement-bone interface. 


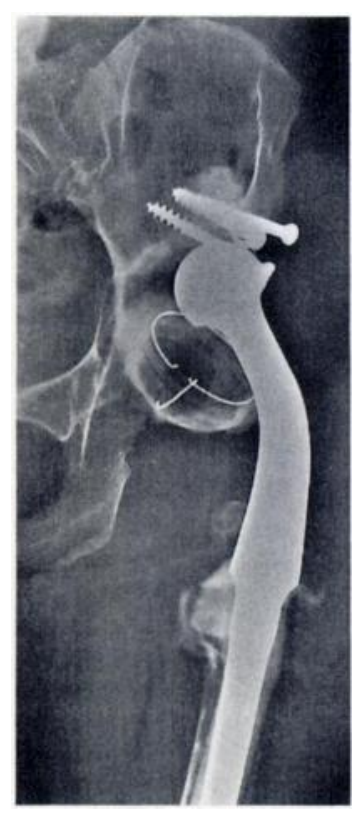

Fig. 4a

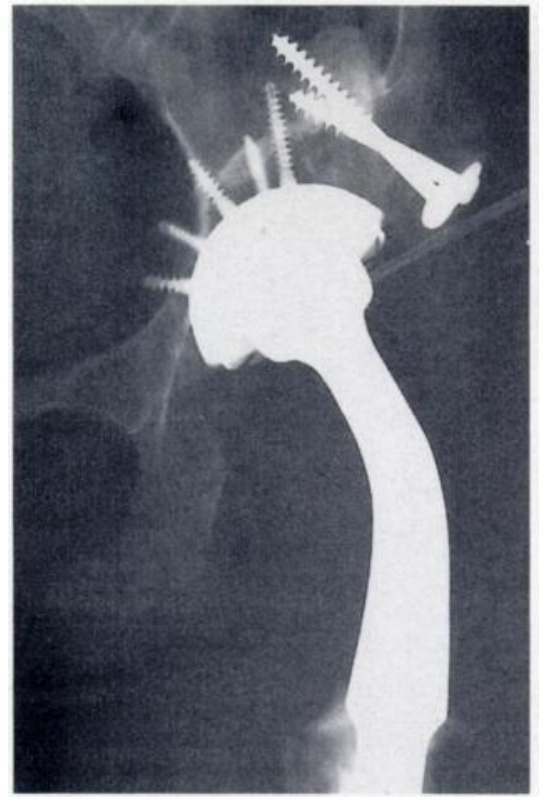

Fig. $4 \mathrm{~b}$

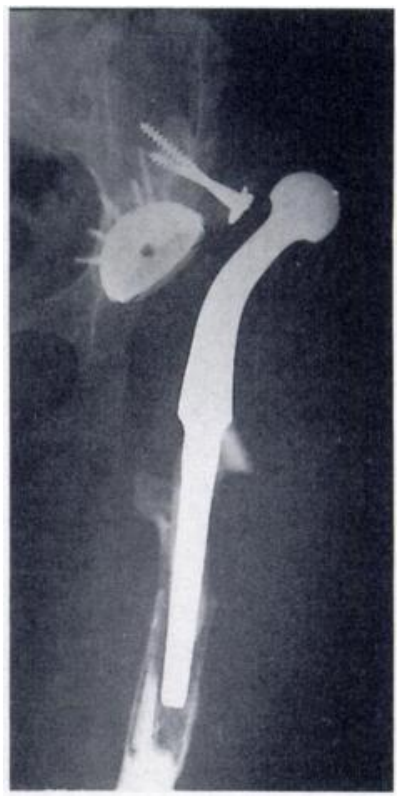

Fig. $4 \mathrm{c}$

Fig.4d

Figure 4a - A 46-year-old woman with a failed acetabular component eight years after proximal femoral replacement. Figure $4 b$ - Revised to porous acetabular component with femoral head allograft. Figure $4 c-$ Loosening of the femoral component and dislocation 14 years after proximal femoral replacement. Figure $4 \mathrm{~d}-$ Femoral component revised to an allograft prosthetic composite with step-cut osteotomy and intramedullary fixation.

because of aseptic loosening; three of these were salvaged with an allograft prosthetic composite (bioimplant) (Fig. 4) and the other with a second-generation proximal femoral replacement prosthesis. The mean age of these four patients was 44 years. In another patient the component fractured at the host-stem junction; this was also revised to an allograft prosthetic composite (bioimplant). Two other femoral components required revision because of recurrent dislocation and were successfully replaced by longer prostheses. There were seven acetabular revisions because of aseptic loosening and two after recurrent dislocation.

Complications. There were 11 dislocations, an overall rate of $22 \%$. Seven were managed by closed reduction followed by a hip spica cast or a brace. Two femoral components and two acetabular prostheses required revision to ensure stability.

There were three cases of deep infection, an overall incidence of $6.3 \%$. Two were treated successfully by debridement and antibiotics; the other was managed by longterm antibiotic therapy with no recurrence when seen 15 years later. Two postoperative haematomas required evacuation. There was one case of iatrogenic sciatic nerve palsy which resolved by three months. Myocardial infarction occurred in two patients perioperatively.

\section{DISCUSSION}

The management of femoral bone loss after failed total hip arthroplasty is a controversial problem. The causes of the bone loss are multifactorial and have been reviewed by several authors (Goldring et al 1983; Jasty et al 1986). The AAOS Committee on the Hip (1990) proposed a classification of femoral deficiency to assist preoperative planning. At revision, the sclerotic proximal femur is often severely deficient in both cortical and cancellous bone (Goldring et al 1983; Kavanagh, Ilstrup and Fitzgerald 1985; Head et al 1987; Poss et al 1988) and the method of salvage depends on the ability to achieve stable fixation in host bone and on the quality of existing bone stock (Poss et al 1988: Allan et al 1991).

The considerable proximal bone loss in our patients precluded the use of conventional long-stem components, and the only alternatives were resection arthroplasty or proximal femoral replacement. We had early success with segmental replacement prostheses in patients with hip tumours (Sim and Chao 1983) and therefore began to use a similar technique in patients with failed total hip arthroplasty and proximal femoral bone loss (Sim and Chao 1981). Our early review included both patients who had non-neoplastic hip disorders with proximal bone loss and those with failed total hip arthroplasties, since they had been managed in an identical fashion. These two groups showed no statistical differences with respect to failure, the incidence of radiolucent lines about the femoral and acetabular components, or postoperative functions such as pain, limp and the use of walking aids.

These preliminary findings indicated that the procedure was valuable in patients for whom resection arthroplasty was the only alternative (Sim and Chao 1981) and the results were encouraging, with only two failures in 21 
Table II. Outcome in 12 patients with failed total hip arthroplasty treated by a proximal femoral replacement prosthesis*

\begin{tabular}{|c|c|c|c|c|c|}
\hline Case & $\begin{array}{l}\text { Age } \\
(\mathbf{y r})\end{array}$ & Sex & $\begin{array}{l}\text { Date of } \\
\text { arthroplasty }\end{array}$ & Failure & Outcome \\
\hline 1 & 28 & $\mathrm{~F}$ & $10 / 74$ & $\begin{array}{l}\text { Loose acetabular component } \\
\text { Loose femoral component }\end{array}$ & $\begin{array}{l}\text { Revised, } 3 / 82 \\
\text { Allograft prosthetic composite, } 3 / 89\end{array}$ \\
\hline 2 & 40 & $\mathbf{M}$ & $3 / 73$ & Loose acetabular component & Girdlestone procedure, 11/76 \\
\hline 3 & 69 & $\mathrm{~F}$ & $1 / 86$ & Loose acetabular component & Revised, 9/90 \\
\hline 4 & 61 & $\mathrm{~F}$ & $7 / 82$ & Recurrent dislocation & Acetabular revision, $8 / 82$ \\
\hline 5 & 44 & $\mathrm{~F}$ & $9 / 76$ & $\begin{array}{l}\text { Loose acetabular component } \\
\text { Loose femoral component }\end{array}$ & $\begin{array}{l}\text { Revised, } 5 / 82 \\
\text { Allograft prosthetic composite, } 6 / 88\end{array}$ \\
\hline 6 & 69 & $\mathrm{~F}$ & $9 / 77$ & $\begin{array}{l}\text { Loose femoral component } \\
\text { Loose acetabular component }\end{array}$ & $\begin{array}{l}\text { Revision to modular proximal femoral } \\
\text { replacement prosthesis, } 11 / 89 \\
\text { Revised to bipolar, } 3 / 91\end{array}$ \\
\hline 7 & 68 & $\mathrm{~F}$ & $6 / 85$ & Recurrent dislocation & Revision acetabular component, 5/86 \\
\hline 8 & 63 & $\mathrm{~F}$ & $7 / 77$ & Recurrent dislocation & $\begin{array}{l}\text { Revision to longer femoral component, } \\
5 / 78\end{array}$ \\
\hline 9 & 30 & $\mathbf{M}$ & $7 / 75$ & Femoral component fracture & Allograft prosthetic composite, $5 / 86$ \\
\hline 10 & 55 & $\mathrm{~F}$ & $1 / 83$ & Loose acetabular component & Revised, 1/90 \\
\hline 11 & 33 & $\mathbf{M}$ & $5 / 80$ & Recurrent dislocation & $\begin{array}{l}\text { Revision to longer femoral component, } \\
9 / 80\end{array}$ \\
\hline 12 & 55 & $\mathrm{~F}$ & $2 / 78$ & $\begin{array}{l}\text { Loose acetabular component } \\
\text { Loose femoral component }\end{array}$ & $\begin{array}{l}\text { Revised, } 9 / 89 \\
\text { Revised, } 9 / 89 \\
\text { Allograft prosthetic composite }\end{array}$ \\
\hline
\end{tabular}

* data from Malkani et al (1993)

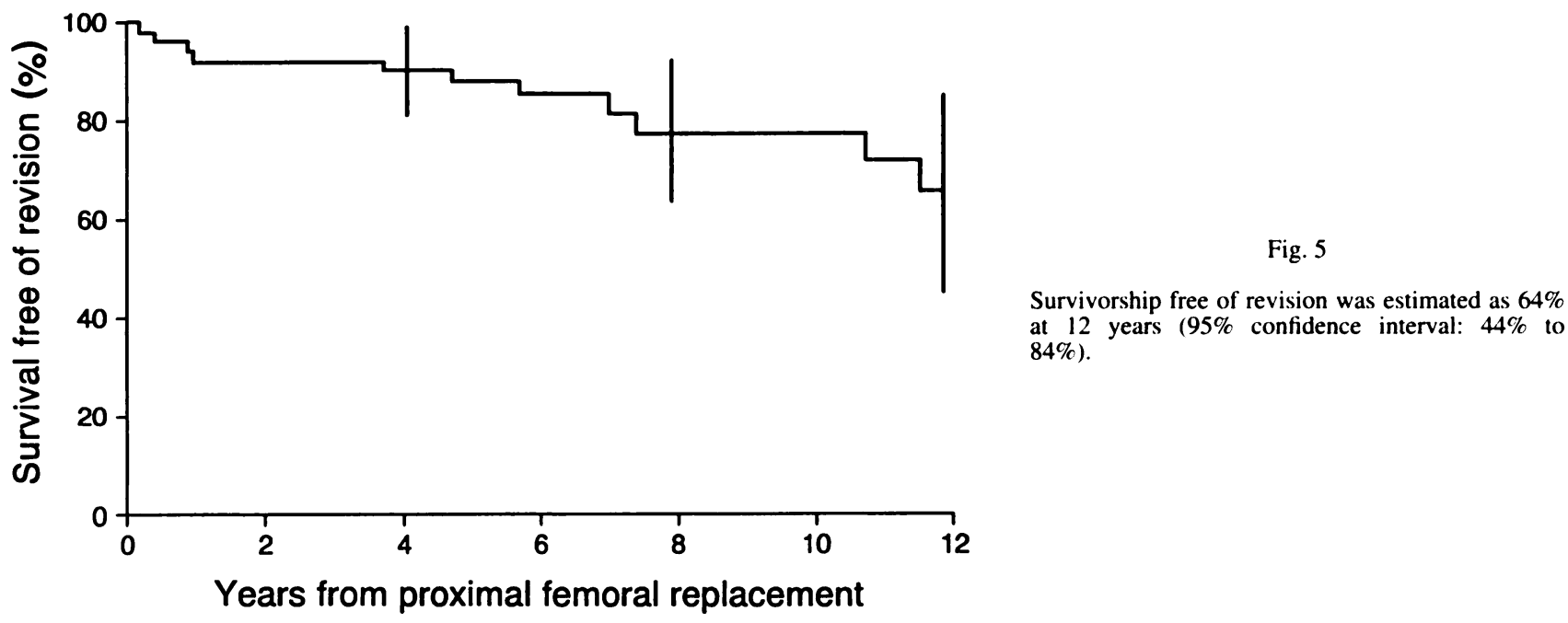

patients. In the last few years other methods of management have become available including resection arthroplasty (Kantor et al 1986), the augmentation of host bone with cortical strut grafts (Allan et al 1991), allograftprosthetic composites (bioimplant) (Gross et al 1985; Head et al 1987; Emerson et al 1990), and the proximal femoral replacement prostheses (Sim and Chao 1981, 1983, 1991; Chao and Sim 1992).

In recent years cortical strut grafts and large whole allografts have been used more commonly to manage loss of proximal femoral bone at revision hip arthroplasty, and we now report our results after a longer follow-up to define better the role of proximal femoral replacement prostheses.
Using any revision as the end point, our results showed an overall survivorship of $64 \%$ at 12 years (Fig. 5). Pain was effectively decreased in $88 \%$ of our patients at one year after operation and in $73 \%$ at the latest review $(p<0.0001)$. Most of the failures were caused by aseptic loosening of the femoral and acetabular components or by recurrent dislocation.

The high rate of loosening of the acetabular component concerned us. The use of a $32 \mathrm{~mm}$ diameter femoral head has been associated with a higher incidence of acetabular component loosening (Morrey and Ilstrup 1989). We now therefore use a modular $28 \mathrm{~mm}$ femoral head size with our second-generation proximal femoral replacement pros- 
thesis. Aseptic loosening of the femoral component and the high incidence of progressive radiolucent lines about them are also a cause for concern. The use of first-generation cementing techniques and the high stresses generated by this type of prosthesis at the cement-bone interface (Chao and Sim 1992) were contributory factors.

Dislocation of the femoral component was our most common complication and was associated with multiple previous procedures and abductor insufficiency (Woo and Morrey 1982). Four of the 11 dislocations required revision. The high rate of dislocation is comparable with that encountered in hip salvage with an allograft prosthetic composite (bioimplant) in which abductor insufficiency would be expected (Gross et al 1985; Head et al 1987; Emerson et al 1990).

We have been able to decrease the incidence of dislocation of our second-generation replacement prosthesis by better understanding of the abductor mechanism and the need for postoperative bracing, and by obtaining adequate soft-tissue tension about the hip (Chao and Sim 1992). The preliminary results with a new modular proximal femoral prosthesis show no failures due to aseptic loosening and only two dislocations in 47 hips (4.3\%) (Chao and Sim 1992).

All failures due to aseptic loosening of the femoral components were salvaged with an allograft prosthetic composite (bioimplant), except in one patient who was 80 years old and was managed successfully with a secondgeneration modular prosthesis. We now attempt to restore proximal femoral bone deficiency with cortical strut grafts, relying on the host bone for stability. If this augmentation is unsatisfactory an allograft prosthetic composite (bioimplant) is used. Preliminary reports of the use of an allograft prosthetic composite (bioimplant) have raised concerns about infection, dislocation, allograft fracture and nonunion at the host-allograft junction (Gross et al 1985; Head et al 1987; Emerson et al 1990), but we consider that, especially in young patients, this may help to restore bone stock for future needs. We now limit the use of a proximal femoral replacement prosthesis to elderly and inactive patients who present with massive bone loss.

No benefits in any form have been received or will be received from a commercial party related directly or indirectly to the subject of this article.

\section{REFERENCES}

AAOS Committee on the Hip. Classification and management of femoral defects. Scientific exhibit. American Academy of Orthopaedic Surgeons Annual Meeting, New Orleans, 1990.

Allan DG, Lavoie GJ, Rudan JF, Gross AE. The use of allograft bone in revision total hip arthroplasty. In: Friedlaender GE, Goldberg VM, eds. Bone and cartilage allografts: biology and clinical applications. Park Ridge, Illinois: AAOS, 1991:255-78.

Chao EYS, Sim FH. Composite fixation of salvage prostheses for the hip and knee. Clin Orthop 1992:276:91-101.

DeLee JG, Charnley J. Radiological demarcation of cemented sockets in total hip replacement. Clin Orthop 1976;121:20-32.

Emerson RH, Head WC, Malinin TI, Matlin JA. Allograft femoral reconstruction in revision hip arthroplasty. Part I. Surgical Rounds for Orthopaedics 1990; July:15-22.

Goldring SR, Schiller AR, Roelke M, et al. The synovial-like membrane at the bone-cement interface in loose total hip replacements and its proposed role in bone lysis. J Bone Joint Surg [Am] 1983;65-A:57584.

Gross AE, Lavoie MV, McDermott P, Marks P. The use of allograft bone in revision of total hip arthroplasty. Clin Orthop 1985; 197:115-22.

Head WC, Malinin TI, Berklacich F. Freeze-dried proximal femoral allografts in revision total hip arthroplasty: a preliminary report. Clin Orthop 1987;215:109-21.

Jasty MJ, Floyd WE III, Schiller AL, Goldring SR, Harris WH. Localized osteolysis in stable, non-septic total hip replacement. $J$ Bone Joint Surg [Am] 1986;68-A:912-9.

Kantor GS, Osterkamp JA, Dorr LD, et al. Resection arthroplasty following infected total hip replacement arthroplasty. J Arthroplasty 1986;1:83-9.
Kaplan EL, Meier P. Nonparametric estimation from incomplete observations. J Am Stat Assoc 1958;53:457-81.

Kavanagh BF, Ilstrup DM, Fitzgerald RH Jr. Revision total hip arthroplasty. J Bone Joint Surg [Am] 1985;67-A:517-26.

Kavanagh BF, Fitzgerald RH Jr. Clinical and roentgenographic assessment of the total hip arthroplasty: a new hip score. Clin Orthop 1985; 193:133-40.

Malkani AL, Sim FH, Chao EYS. Custom-made segmental femoral replacement prosthesis in revision total hip arthroplasty. Orthop Clin North Am 1993:24:727-33.

Morrey BF, Ilstrup DM. Size of the femoral head and acetabular revision in total hip-replacement arthroplasty. J Bone Joint Surg [Am] 1989; 71-A:50-5.

Poss R, Walker P, Spector M, et al. Strategies for improving fixation of femoral components in total hip arthroplasty. Clin Orthop 1988:235:181-94.

Sim FH, Chao EYS. Hip salvage by proximal femoral replacement. J Bone Joint Surg [Am] 1981:63-A:1228-39.

Sim FH, Chao EYS. Segmental prosthetic replacement of the hip and knee. In: Chao EY-S, Ivins JC, eds. Tumor prostheses for bone and joint reconstruction: the design and application. New York: ThiemeStratton, 1983:247-66.

Sim FH, Chao EYS. Proximal femoral replacement. In: Morrey BF. ed. Joint replacement arthroplasty: New York: Churchill Livingstone, 1991:820-33.

Woo RYG, Morrey BF. Dislocations after total hip arthroplasty. $J$ Bone Joint Surg [Am] 1982;64-A:1295-306. 